\title{
O ethos de um guerreiro: 0 testemunho de Reynaldo Gianecchini sobre o câncer
}

\section{Roberto Abib}

Universidade Federal do Rio de Janeiro, Escola de Comunicação, Rio de Janeiro, RJ, Brasil ORCID: http://orcid.org/0000-0001-5036-8100

\section{Igor Sacramento}

Fundação Oswaldo Cruz , Rio de Janeiro, RJ, Brasil

ORCID: http://orcid.org/0000-0003-1509-4778

\section{Resumo}

A partir de reconfigurações na produção da subjetividade pela circulação do ethos terapêutico na contemporaneidade, este trabalho analisa a enunciação da entrevista do ator Reynaldo Gianecchini no programa Fantástico, da TV Globo, considerando não apenas o conteúdo textual, mas a forma enunciativa de um testemunho intimista atravessado pelos ideais da superação e de responsabilização de si na retomada da autonomia (da vida) diante da experiência de um processo de tratamento de câncer.

\section{Palavras-chave}

Testemunho. Celebridade. Televisão. Câncer. Ethos terapêutico.

\section{Introdução}

Na cultura contemporânea, as celebridades estão sendo cada vez mais instadas a falar sobre si, especialmente sobre suas experiências de sofrimento (separação, adoecimento, problemas financeiros, transtornos, frustrações, decepções). Desse modo, há uma mudança significativa no status de celebridades. Elas deixaram de ser majoritariamente representadas pelos signos da perfeição e da infalibilidade e passaram a ser mostradas publicamente como imperfeitas e infalíveis (SACRAMENTO, 2015). A mídia, contemporaneamente, com frequência, apresenta a "realidade suja", imperfeita, da vida das celebridades (HARPER, 2006, p. 312). De diferentes formas, a constituição delas como vítimas sofredoras pode ser tão ou mais lucrativa do que aquelas construções como heróis ou heroínas inabaláveis - olimpianos (MORIN, 1979). Além disso, é cada vez maior a 
construção discursiva de celebridades e o interesse por elas como "elas realmente são", por meio de tropos de intimidade, de reflexividade e de autenticidade (LITTLER, 2004).

Como Jo Littler (2004, p. 13) sugere, é por meio da "combinação de reflexividade sobre o negócio de ser uma celebridade, a interioridade emocional e a autocrítica em oferta" que alguém é "convidado a sentir com seus sentimentos". A celebridade, então, supostamente abre um espaço onde o real substitui o artificial ou fabricado. 0 público chega a vê-las como elas realmente são (HOLMES, 2005). Quando se trata das particularidades da celebridade confessional, os processos de resgate envolvem a cumplicidade ativa do público. "Para os fãs são solicitados a concessão de perdão em relação a fraquezas de personalidade ou comportamento negativo que contrasta com a imagem idealizada da celebridade, ou reconhece a vulnerabilidade e fraqueza da celebridade" (ROJEK, 2008, p. 89).

Partindo da premissa de que a "tirania da intimidade" (SENNETT, 1999) formou as condições em que as celebridades trabalhem a si mesmas cada vez mais como sujeitos emocionais na cena pública, e que as relações sociais são consideradas "autênticas" ou "reais" principalmente por meio do compromisso delas com elas mesmas (SACRAMENTO, 2015). Os reality shows, a autobiografia, as redes sociais online e a entrevista cara a cara se tornaram veículos para a produção de intimidade com as celebridades por meio da transmissão da história da vida. Eles fornecem plataformas por meio de formatos padronizados para encenar e enquadrar a vida de celebridades e, crucialmente, fornecem mecanismos para a expressão de dispositivos culturais dominantes de autocompreensão: confissão, introspecção e a reapresentação de um eu melhor ou melhorado.

As exigências pela expressão emocional de celebridades na cultura midiática contemporânea tornam a intimidade como a condição básica para a verdade. Nesse contexto, há uma gama diversa de espaços culturais em que o trabalho de emoção de celebridade acontece. As convenções que permitem esse trabalho participam de um processo de construção da intimidade pública contínua para as celebridades (MARSHALL, 1997). A relação público-celebridade cruza-se com um imperativo cultural mais amplo, o ethos terapêutico.

Como Frank Furedi (2004, p. 22) explica, "uma cultura torna-se terapêutica quando a forma de pensar se expande de informar a relação entre o indivíduo e o terapeuta para moldar as percepções do público sobre uma variedade de questões". Referir-se a uma cultura como terapêutica é sugerir que os roteiros sociais, as lentes e os vocabulários por 
meio dos quais as pessoas se entendem e suas vidas são fortemente influenciados pela linguagem orientada para o interior da terapêutica (com conversas sobre sentimentos, apegos, autoestima, ansiedade, estresse, bem-estar, segurança , trauma, perda, luto e assim por diante).

O próprio Furedi (2004, p. 23) se abstém de definir a "cultura terapêutica", como ele a chama, porque está "ainda em processo de transformação". Isso, no entanto, permite que ele a defina implicitamente de qualquer forma que sirva ao seu objetivo retórico de atacá-la. Ele vê isso como sendo tudo sobre a imposição do discurso de especialistas, de tal forma que a prescrição de terapia especializada é sempre o objetivo. Ele mostra que a linguagem terapêutica espalhou-se de tal maneira que ampliou enormemente o raio de psiquiátrica patologização e reificação do que seriam predicamentos humanos comuns, e, ao fazê-los, imputa fraqueza, déficit, vulnerabilidade e dano a pessoas comuns, em que o cuidado de si mesmas se configura como um estoicismo espontâneo. Furedi (2004) acusa a cosmovisão terapêutica do individualismo, especificamente do determinismo emocional, implicando, na maioria das vezes, a substituição de uma ética de responsabilidade e culpa por elogios para aqueles que confessam seus pecados.

Eva Illouz (2011) afirma que estar de posse de um tipo particular de competência emocional, uma espécie de capital terapêutico, é um valor importante para os indivíduos de hoje. Esta ideia pode estar ligada a novas exigências para o cidadão ideal nas democracias ocidentais de ser capaz de gerenciar a si mesmo como um indivíduo autônomo e enfrentador (ROSE, 1996). Uma preocupação é, portanto, que a política abdica em favor de fórmulas individuais e psicológicas. Uma forma generalizada de discurso que ilustra a expectativa de que os indivíduos devem tomar medidas em suas vidas é que é preciso trabalhar consigo mesmo. Nesse sentido, como caracteriza o ethos terapêutico, a revelação de um trauma, de uma doença e de outro tipo de infortúnios é muitas vezes acompanhada por testemunhos de resistência e sobrevivência que se baseiam na capacidade do indivíduo de transcender uma dificuldade levando a um estado - ou estado parcial - de autorrealização (ILLOUZ, 2011).

Segundo Illouz (2011), o discurso terapêutico fornece uma nova linguagem de identidade que prescreve estratégias de ação que podem ajudar homens e mulheres em todas as faixas etárias e classes sociais a implementar certas definições de uma vida boa (e idealmente alcançá-las). Neste contexto, o objetivo de "ser você no seu melhor" pode ser interpretado não como um ideal superficial e inatingível de felicidade interminável ou fama 
e fortuna hollywoodianas, mas sim como um ideal mais tangível e universal. Ainda assim, este discurso de vida ideal é algo que obriga a estar em constante busca de melhorias e remédios para o crescimento pessoal. Illouz (2003) revelou como o ethos terapêutico na verdade ajudou homens e mulheres a estarem em posição de mais ou menos isoladas na esfera privada em participação e demanda na esfera pública.

Uma marca da cultura terapêutica contemporânea é um nível maior de abertura - em contraste com reticentes anteriores - sobre problemas de vida pessoal e saúde mental, muitas vezes manifestos em relatos públicos de problemas privados. De acordo com Nikolas Rose (1996), a forma contemporânea de "falar publicamente" (speak out) surgiu da fusão da prática política radical dos anos 1960, da conscientização, com um ethos terapêutico de autorrealização. Esse tipo de fala (speak out) expressa o sentimento e a necessidade de se falar franca e publicamente sobre o que se passa internamente. Rose (1996, p. 43) sugere que "ao invés de um pecador representando aqueles que falam, hoje são cada vez mais sobreviventes testemunhando lesões ocultas feitas a eles - ou pelo destino".

O programa Fantástico, da Rede Globo, apresenta com frequência quadros nos quais há a narração por meio da mediação da fala do entrevistado pela interlocução com o entrevistador na constituição de narrações biográficas sobre experiências pessoais do câncer, tornadas públicas por meio da exposição midiática. É o caso do ator Reynaldo Gianecchini, que teve um câncer linfático e concedeu uma entrevista em 18 de novembro de 2011 ao programa, o qual a exibiu com a chamada "Fantástico entrevista o ator Reynaldo Gianecchini: Eu quero a vida", material de análise deste trabalho. Pressupõe-se que as tecnologias de comunicação, no caso, o meio televisivo, são vistos ao mesmo tempo como constituinte e constituidor de uma ordem social, sendo que a sua materialidade e seu modo de produção participa de uma cultura.

Partimos também do pressuposto de que os testemunhos e os relatos das experiências pessoais caracterizam-se como mais críveis e necessários na contemporaneidade em detrimento de conhecimento originado por dados ou fatos considerados objetivos. Afinal, vivemos um momento chamado e compreendido como passando por uma guinada subjetiva (SARLO, 2007). Além disso, no contemporâneo, entendemos que a produção da subjetividade passa por ideais de superação, daí a sensação de um aumento na mídia de relatos de experiências de doenças e transtornos, mas também de infortúnios da vida (separação, acidentes, violências, desemprego), acompanhados com esses ideais, de que é preciso vencer esse momento ruim por meio da capacidade individual 
de autogestão das emoções e de autoaprimoramento. Para Sacramento (2015), esta narrativa que constituiu o processo de produção de subjetividade na contemporaneidade se caracteriza pelo ethos terapêutico.

O ethos terapêutico realça esta necessidade de autorrealização no mundo, pois é "caracterizado por uma preocupação excessiva com a saúde, psíquica e física" (SACRAMENTO, 2015, p. 111). Para o autor, o ethos terapêutico se apresenta como um dispositivo da cultura que exige dos indivíduos alcançarem formas de bem-estar e felicidade plenas como partes de um processo de autorrealização. Nesse sentido, por exemplo, o relato da experiência com a doença se desloca de uma concepção de doença como um enfraquecimento do indivíduo e passa a se configurar como um ponto zero. Nele, o sujeito é convocado a rever seus hábitos e seu estilo de vida, encarando a doença como uma oportunidade para o autoconhecimento e para o autoaprimoramento, e também como algo a ser superado para a conquista da felicidade plena.

Compreendemos que a linguagem terapêutica não se dá a partir dos meios de comunicação, pois ela circula no tecido social e uma de suas expressões se dá nos relatos midiáticos. Tal entendimento vai ao encontro dos pressupostos de Nick Couldry (2004), que compreende o estudo da mídia para além da análise textual das mensagens, da audiência e do consumo, mas como uma prática que constituiu outras práticas sociais. Segundo ele, "os meios de comunicação representam outras práticas, as quais, portanto, sofrem consequências diretas da mídia nas suas maneiras de se ordenar e definir" (COULDRY, 2004, p. 123). Couldry (2004) discorre que a cultura das celebridades é um dos exemplos da presença fluída da mídia na vida cotidiana por conta da identificação pelo público com o modo de ser do seu ídolo. Dessa forma, os testemunhos das celebridades são um dos muitos exemplos do ethos terapêutico contemporâneo. Uma de suas implicações está na própria relação entre celebridades e públicos. Há um processo de identificação - e mais do que isso, em muitas vezes a formação de uma "comunidade de sofrimento" (ILLOUZ, 2011) - diante do sofrimento dos célebres. Essa identificação pelas experiências e narrativas de sofrimento, 
mas também de superação, demonstram o quanto que o ethos característico de nossa sociedade é o terapêutico (SACRAMENTO; RAMOS, 2018). ${ }^{1}$

Em termos analíticos, acionamos a noção de ethos como elemento fundamental para a observação das relações entre a linguagem televisiva e os processos de subjetivação na entrevista feita pelo Fantástico com Reynaldo Gianecchini em 18 de novembro de 2011. Utilizamos procedimentos analíticos semelhantes de outros trabalhos já realizados (SACRAMENTO; BORGES, 2017a, 2017b), tendo os seguintes operadores analítico: a relação entre entrevistado e entrevistado; a performance da intimidade e da autenticidade; o contexto comunicativo como uma cena fiadora e a relação com o público.

Nesse contexto, produz-se uma midiatização do ethos testemunhal, que "enfatiza uma nova lógica do testemunhal, centrada na articulação do indivíduo com sua imagem" (SACRAMENTO; BORGES, 2017b, p. 70). Sendo assim:

Tal processo não faz do caráter do enunciador uma imagem (pela concretude da argumentação e da presença diante dos enunciatários, na retórica clássica), mas produz o próprio enunciador como uma imagem (pela virtualização da presença e da argumentação, na retórica midiatizada). (SACRAMENTO; BORGES, 2017b, p. 70-71).

Nesse contexto, a confiança está cada vez mais associada tanto à imagem quanto à encenação da autenticidade pela exposição da intimidade:

Há uma nova organização da nossa relação com verdade e com a realidade, profundamente marcadas pela crença nas imagens (especialmente quando elas encenam a vida íntima não só como conteúdo, mas também como forma enunciativa - edição, jogo de cena, elementos cenográficos, qualidade da imagem, se amadora ou não). (SACRAMENTO; BORGES, 2017b, p. 71).

\footnotetext{
A noção de ethos neste artigo é usada em diferentes acepcões. A etimologia de ethos, do grego, significa a casa, a morada, o habitar, mas também costumes, crenças e hábitos. Desse modo, considerar o ethos como uma casa, como uma habitação, é considerar o modo humano de habitar o mundo numa determinada época, isto é, traz à consideração os códigos, valores, ideais, posturas, condutas para consigo mesmo e para com os outros, algo equivalente à moradia. Na sua reflexão sobre ética, Michel Foucault reconhece o ethos como espaço de instituição de uma troca regulada de afetos e obrigações entre os indivíduos: "não há outro fim nem outro termo além do propósito de estabelecer-se junto a si, 'residir em si mesmo', fazer aí sua morada" (FOUCAULT, 2010, p. 256). 0 ethos, nesse sentido, é a morada do ser: uma condição criada para que o indivíduo em seu processo de constituição como sujeito possa desenvolver, pelo exercício e pelo hábito, relações estabelecidas consigo e com os outros baseadas em saberes, valores, crenças e jogos de poder e verdade. A outra acepção de ethos diz respeito à tradição retórica, apropriada pela análise de discursos contemporânea, entendendo, por um lado, a "imagem de si no discurso" (AMOSSY, 2018), e, por outro, mais amplamente como o processo de construção do caráter do enunciador (de sua confiança) numa determinada situação comunicativa em conexão com as outras interações comunicativas e com os valores morais de uma época (PINTO, 2009).
} 
Nesse regime de verdade, tal qual de uma produção de efeito de real como um "efeito de vida real" pelas imagens, pela fala de si, íntima, reveladora, em primeira pessoa, num relato próprio sobre o que viveu ou o que se está vivendo (ARFUCH, 2010, p. 67). Nesse contexto comunicativo, "por meio das imagens e das opções de edição, cenografia, figurino, encenação e jogo cênico ente entrevistadora e entrevistado, confiamos na realidade da miseen-scène" (SACRAMENTO; BORGES, 2017b, p. 83). A relação de confiança com a encenação dos acontecimentos reconfigura-se com o imperativo terapêutico contemporâneo.

\section{A linguagem terapêutica: sabedoria e controle sobre si}

No início da entrevista com o ator, percebe-se a compreensão da morte (finitude) como a possibilidade de pensar sobre a vida. Gianecchini relata esse estado como uma fase de entendimento ao estar diante da doença, considerando-a como uma proximidade da morte; e a morte concretizada do pai, que faleceu por conta de um câncer:

Gianecchini: Tem sido um processo de muito entendimento desde que eu recebi a notícia da minha doença e todos os acontecimentos depois. 0 fato de eu ter um pai também com essa doença, que já estava antes de eu saber da minha. Então assim, quando você depara com a questão da morte e ela tão próxima, você começa a analisar o que você tem de concreto, que é o presente. Vem pensamento daquele presente. Meu pai acabou falecendo.

O ator segue contando como foi a despedida do pai, dirigindo-se a ele para reafirmar todo o seu amor, dizendo que iria cuidar da família, pedindo perdão e que também perdoava pelas coisas que poderiam ter sido e não foram. Nesse sentido, compreendemos que a experiência moderna no qual o homem em sua finitude depara com os limites da existência mas que também é capaz de transformá-la - na contemporaneidade, se reconfigura nos testemunhos sobre a experiência da doença, compreendida como um momento zero em que a autonomia sobre a vida é abalada e que, portanto, é preciso retomá-la. Esta é uma das manifestações que Illouz (2011) define como a narrativa terapêutica que se produz na contemporaneidade, em que os relatos se concentram na descrição detalhada de histórias pessoais desafortunadas, sofridas e angustiantes, mas também relatos que abrandam ou enfatizam determinadas situações vividas para que sejam parte de um testemunho público de superação dos problemas e de recuperação da saúde e do bem-estar por meio de um gerenciamento eficaz de si. Nas narrativas contemporâneas, não é mais apenas o sucesso 
que move as histórias que são contadas ao público, mas "exatamente a possibilidade de que o eu possa se desestruturar em meio ao sucesso mundano" (ILLOUZ, 2011, p. 79).

O ethos terapêutico contemporâneo transforma os sentimentos em objetos públicos, a serem expostos, disputados e debatidos. Assim, o sujeito passa a participar da esfera pública por meio da interpretação e da exposição de sofrimentos íntimos com a intenção de demonstrar aquilo que impede a felicidade, sobretudo a possibilidade de efetivar processos de autorrealização, e o modo como foi possível superar os obstáculos. Enquanto a felicidade ou a superação é característica de um sujeito ativo e pleno de capacidade de autogestão, o discurso terapêutico na cultura contemporânea produz sujeitos que se sentem em diversas experiências da vida cotidiana (casamento, separação, escola, trabalho, reunião familiar) vulneráveis, frágeis ou em riscos de perderem a si mesmos diante de um mundo repleto de adversidades e tormentas (FUREDI, 2004).

A ideia de um vencedor da doença aparece no texto de apresentação (na cabeça) da entrevista, em que o apresentador Zeca Camargo em voz off anuncia: “O Fantástico está no ar com o depoimento de um guerreiro". Na sequência, é incluída a fala e a imagem da entrevista em que Gianecchini expressou isso: "um guerreiro mesmo". Ou seja, já de início o espectador é interpelado a conhecer a história de uma celebridade que irá relatar uma experiência de superação, no caso, um câncer vencido. Esta fala editada na chamada do conteúdo é o momento da entrevista em que a apresentadora e o ator comentam sobre como foi a escolha de raspar a cabeça antes dos cabelos começarem a cair devido às sessões de quimioterapia. Gianecchini relembra a novela Laços de Família, de Manuel Carlos, na qual interpretava o marido da personagem Camila (Carolina Dieckmann). Na cena, Camila, que enfrentava a leucemia, via aos prantos seus cabelos sendo raspados diante do espelho (câmera). 0 ator relata: "É muito maluco eu estar vivendo isso no dia, da pessoa raspando minha cabeça. Eu só pensava nisso. Olha, na ficção eu estava chorando muito. Na minha vida real, eu me achei a cara de um guerreiro. Parecia um guerreiro mesmo". Ao fazer essa comparação com a ficção, o ator autentifica a superação da doença e a sua identidade de guerreiro no âmbito da realidade, da verdade, do elemento mais básico e autêntico do entrevistado.

O discurso terapêutico gerou uma nova linguagem da individualidade que é rivalizada apenas pelo liberalismo político e pela linguagem de eficiência econômica baseada no mercado em sua adoção por atacado. Com o capitalismo, a linguagem da terapia foi globalmente adotada pelas instituições da corporação e da família, ilustrando assim 
como a cultura e o conhecimento estão interligados. Bellah (1985) associa o ethos terapêutico com a necessidade de encontrar o "eu verdadeiro", que é a única fonte de relacionamentos genuínos com outras pessoas. Ilouz (2008) argumentou que, ao longo do tempo, o ethos terapêutico passou a definir um estilo emocional dominante no Ocidente, compreendendo novas maneiras de pensar sobre o self, suas relações com os outros e suas potencialidades. Seria errado, no entanto, entender o ethos terapêutico como simplesmente uma institucionalização de autenticidade. Diversos trabalhos exploraram as fontes mais profundas do ethos terapêutico nas tradições americanas anteriores de individualismo expressivo e autoajuda religiosa. Mas o ethos terapêutico teve uma história contestada desde a primeira vez que chamou a atenção dos críticos culturais nos anos 1960. Em meados do século XX, Philip Rieff (1966) argumentou que o surgimento do "homem psicológico" levara ao "triunfo da terapia".

Como Illouz (2011), consideramos o ethos terapêutico como um "estilo emocional" que está ligado a novas técnicas de autocontrole e autogerenciamento. Entendemos o neoliberalismo para os propósitos deste artigo como uma racionalidade política que busca generalizar a noção de liberdade autogovernada por toda a sociedade, transformando os sites de solidariedade e coletivismo em formas de competição estruturada. Argumentamos que, para julgar adequadamente a questão do valor da autenticidade e sua relação com a sensibilidade terapêutica, é necessário situar essa questão no contexto do crescimento das formas de governo neoliberais. Como Nikolas Rose (1990) argumentou, uma simbiose emergiu entre atitudes e estilos e as novas formas de gestão que foram desenvolvidas como técnicas de governança neoliberal. Isto teve consequências deletérias para o ideal ético de autenticidade. Argumentamos que a autenticidade foi pressionada para o serviço de tornar significativo e ajudar a sustentar noções distintamente neoliberais de responsabilidade individual e de cidadania pelo consumo.

A autenticidade entrou efetivamente em colapso na forma de liberdade terapêutica autogerida que Rose (1990) chama de autonomia. As novas tecnologias do governo não funcionam esmagando ou sufocando subjetividade no interesse de um propósito maior e comum; eles procuram "alinhar política, objetivos sociais e institucionais com prazeres e desejos individuais e com a felicidade e realização do ego" (ROSE, 1990, p. 261). As novas técnicas de autogestão, Rose (1990) afirma, são fundamentalmente, "terapias da liberdade", cujo objetivo é remodelar a subjetividade de acordo com as suas preferências de escolha e concorrência. 
Nos últimos minutos da entrevista, a apresentadora informa que o ator terá de fazer um autotransplante, que é explicado por meio de imagem gráfica e com sua voz em off. Após a explicação, volta-se a imagem na entrevista. Patrícia Poeta quer saber como ele está se sentindo para esse novo procedimento:

Patrícia Poeta: Como é que você está se sentindo para esse momento? Como é que está sua expectativa para esse momento?

Gianecchini: Eu me sinto curado desde o primeiro dia, engraçado isso. Eu não jogo com essa possibilidade de perder, embora tudo possa acontecer na vida, mas eu acredito muito na força da vida.

Observa-se que, pelo depoimento do ator, o enfrentamento da doença é como se fosse um jogo. Para Ehrenberg (2010), a prática e a linguagem esportiva penetraram em todos os poros da sociedade e representam a forma do governo de si na contemporaneidade. 0 sujeito de uma sociedade pós-disciplinar ${ }^{2}$ passa a ser o empresário de si mesmo, um jogador cuja missão está sempre em superar seus limites. Em todas as esferas da sociedade, o indivíduo é convocado a superar os desafios impostos no cotidiano do trabalho e nos infortúnios da vida. 0 fim do jogo é a sua felicidade pessoal. Desta forma, a constituição do sujeito, a partir da lógica do esporte e da aventura, produz um ideal de libertação, ao invés de uma moral de assujeitamento e alienação, pressupostos da sociedade industrial. Quando a prática esportiva se torna um sistema de condutas de si, ela é compreendida como uma "técnica de fabricação da autonomia, uma aprendizagem do governo de si mesmo que se desenrola tanto na vida privada quanto na vida pública" (EHRENBERG, 2010, p. 20).

No encerramento da conversa, a entrevistadora interroga o ator com uma pergunta cujo sentido denota que o fim do tratamento é uma retomada da autonomia da vida ou um renascimento:

Patrícia Poeta: Quando você tiver vencido tudo isso, tiver passado pelo transplante, qual vai ser a primeira coisa que você vai querer fazer?

Gianecchini: Nossa, eu não tinha pensado nisso (silêncio). Me veio na minha mente entrar no mar. Eu tenho uma relação louca assim com o mar. É... Eu gosto muito e sinto falta.

2 A partir da reflexão de Michel Foucault sobre a sociedade disciplinar, Gilles Deleuze propõe a formação da sociedade de controle, materializada nas dinâmicas da empresa, que tem como característica promover a concorrência entre os indivíduos, dividindo-os em si mesmo. Ehrenberg denomina de sociedade pós-disciplinar, marcada pela necessidade dos sujeitos buscarem continuamente a superação dos seus limites nas práticas sociais, não somente nas esportistas. 


\section{Intimidade em cena: o modo de ser celebridade}

No decorrer da entrevista são inseridas imagens de arquivo da imprensa, com datas do ocorrido, e vídeos amadores como documentos que comprovam e ilustram a reconstituição do tratamento do ator, demostrando o interesse midiático e do público pelo processo terapêutico de Gianecchini. Ao comentar sobre como foi a primeira internação que durou 26 dias, explicado em voz off por Patrícia Poeta, é incluída na edição um vídeo amador com o depoimento dele em frente ao hospital, rodeado de fãs o ator declara: "Quero dizer que estou muito forte. Que essa minha força vem de grande parte do carinho todo. Desse amor, dos amigos. Das pessoas que tenham me mandado e-mail. Tenho lido todos". Ao voltar para a conversa, a entrevistadora e o ator discorrem sobre o carinho dos fãs e amigos:

Gianecchini: Essas pessoas todas que me escrevem, desde os meus amigos, os mais queridos, até os menos conhecidos e até os totalmente desconhecidos, que eu recebo, que mandam cartas para o hospital, ou descobrem o meu e-mail. Essas pessoas me emocionam demais.

Patrícia Poeta: Você imaginava que era tão querido pelos brasileiros?

Gianecchini: Não, honestamente não. Foi uma surpresa. E essa parte me emociona. Essa parte que me faz chorar.

Patrícia Poeta: Que bom, é de felicidade.

Gianecchini: É de felicidade, demais, demais...

Na contemporaneidade, a mídia busca extrair das celebridades a substância humana de identificação pela exposição de detalhes da vida privada, mostrando que eles passam por muitas situações por que todos nós passamos e por outras que não vivemos, mas que lhe dão humanidade pela falibilidade: a dor, a traição, o acidente, o preconceito, a catástrofe, a doença, o vício e a morte.

A cultura contemporânea das celebridades implica práticas e condutas marcadas pela encenação da intimidade com o público (REDMOND, 2006). A construção da subjetividade dos célebres tem se reconfigurado pela linguagem terapêutica. Ela não é mais um herói acabado imbuído da moral e ética divina como sugere (MORIN, 1979) na era dos olimpianos. No contemporâneo, sua vida exemplar e heroica é marcada pela superação dos infortúnios da vida. Este valor é reconhecido e identificado pelo público, e que, portanto, contribui para a subjetivação da celebridade, pois "ao se projetarem na trajetória de vida célebres e se posicionarem em relação a elas, os sujeitos manifestam o desejo de endossar certos valores que consideram importantes em sua própria vida" (FRANÇA; SIMÕES, 2014, p. 1078). 
No programa, a enunciação de privacidade é revelada pela informação de que a entrevista foi feita na casa do próprio ator, pela construção de uma iluminação meia-luz e até mesmo pela postura de Patrícia Poeta, que demonstra intimidade com Gianecchini a partir de algumas declarações feitas antes de fazer as perguntas, tais como: "Sabe o que chamou muito minha atenção, todas as vezes que nos falamos por telefone? Você sempre tinha uma mensagem positiva, e você sempre falava com uma voz de uma pessoa muito feliz" (Figura 1).

Figura 1 - Em sua casa, Gianecchini recebe apresentadora do Fantástico

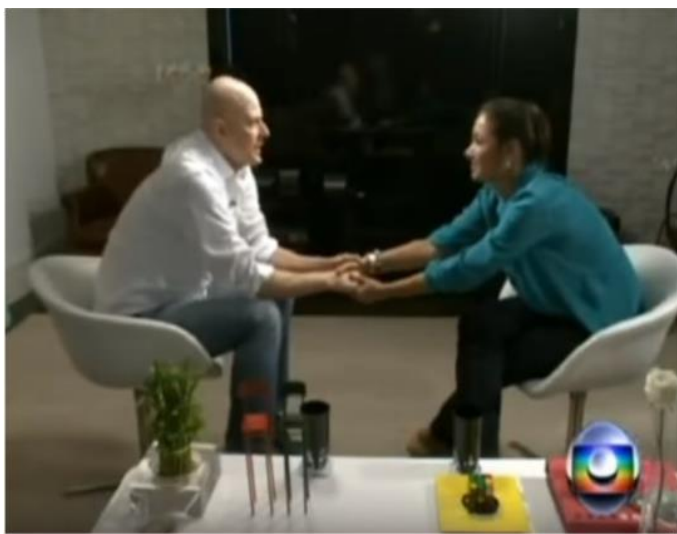

Figura 1

Fonte: print da entrevista (GIANECCHINI, 2011)

Desse modo, a autenticidade da enunciação não se dá apenas pela mobilização dos modos de dizer (palavras, tipos de frase, argumentos etc.), mas também dos modos de mostrar-se (gestos, mímica, direção do olhar, postura, roupas e adornos (PINTO, 2009). Pode-se compreender que a prática midiática do ethos terapêutico de uma celebridade, atravessada pelo caráter de intimidade, se dá por um fenômeno que se constrói dentro da instância enunciativa, no momento em que o enunciador toma a palavra e se mostra pelas marcas enunciativas de modalização da experiência - em gestos, atitudes, falas, vestimentas -, em tudo aquilo que permite estabelecer maior contato e interação dos co-enunciadores (Gianecchini e Patrícia Poeta) como uma estratégia de conquista de intimidade e construção de vínculo com o público (como entidade enunciatária).

Para Dominique Maingeneau (2008), a cenografia não é tão somente um cenário onde o discurso aparece no interior de um espaço já construído e independente dele; ela é a enunciação que, ao se desenvolver, constitui progressivamente - e paradoxalmente - o seu próprio dispositivo de fala. A cenografia é "ao mesmo tempo fonte do discurso e aquilo que 
ele engendra; ela legitima um enunciado que, por sua vez, deve legitimá-la estabelecendo que essa cenografia onde nasce a fala é precisamente a cenografia exigida para enunciar como convém" (MAINGUENEAU, 2008, p. 87-88).

Como estamos mostrando, essa cena se constrói pela ambientação da entrevista: um ambiente doméstico (uma sala de estar), com sofá, móveis, TV e uma poltrona em frente à outra, onde os dois estão sentados. Desde o início da entrevista, sabemos que se trata da casa do ator. Esse é mais um signo da intimidade colocada em cena pela enunciação televisiva de modo a conferir maior veracidade e sinceridade ao dito. A intimidade tem sido na cultura contemporânea um valor fundamental. Essa tirania da intimidade - para remontarmos ao termo usado por Richard Sennett (1999) - implica mutações fundamentais nas narrativas pessoais sobre doenças. Elas passam do isolamento, do tabu, do interdito, para o governo da exposição pública mediada por diferentes tecnologias e dispositivos midiáticos. Além disso, crê-se que as narrativas sobre sofrimentos por parte das celebridades as tornam mais humanas e promovem maior identificação com o público e não só a projeção relação a uma "vida perfeita” (SACRAMENTO, 2015).

\section{Testemunho na contemporaneidade: o eu interior voltado para fora}

A partir do pensamento foucaultiano, Paulo Vaz (1997) argumenta que o homem da idade clássica tinha a tarefa de ordenar o mundo sem questioná-lo a partir de uma reprodução da representação e ordenamento geral já dado. Mas que na modernidade, o homem, em sua interioridade, encontrará a verdade em seu ser "para que seja fundado todo e qualquer conhecimento humano, obrigando cada indivíduo a interiorizá-la e que funda esta verdade em uma história que narra as vicissitudes da descoberta" (VAZ, 1997, p. 42).

Foucault (1977) argumenta que a vontade de colocar o "sexo em discurso" desde a Idade Média não representava a repressão do desejo, mas quanto mais se falava sobre a sexualidade mais se exercia o prazer e o poder inscritos em nosso corpo, que, no século XIX, produziu a ciência do sexo, com suas classificações patológicas e tecnologias como a confissão, dispersas na prática do poder da igreja, do judiciário e nas formas de constituição de nossa existência. De acordo com o autor, a confissão passou a ser uma das técnicas mais valorizadas para produzir a verdade.

Radstone (2006) traz uma explanação do que seria a confissão e o testemunho desde as teorias literárias até o pensamento foucaultiano. A partir do entendimento pelas teorias 
da literatura de que a confissão está comprometida com o Eu, que é examinado, sendo sujeito e objeto do relato; e o testemunho, por outro lado, trata de um relato sobre um evento externo, presenciado pelo sujeito, a autora conclui que há tensões nas teorias sobre o testemunho na contemporaneidade em relação à subjetividade e intersubjetividade, propondo que na contemporaneidade ocorre um movimento da narrativa e do sujeito confessional para um texto e sujeito externo e testemunhal. Sendo assim, o testemunho representa "a virada de fora do eu confessional, de modo que o problema que residia no interior e até mesmo constituía o sujeito, agora é considerado como estando fora de si mesmo" (RADSTONE, 2006, p. 176).

Para Sarlo (2007), a tendência em reconstituir a textura da vida e da verdade a partir da rememoração da experiência "não se trata simplesmente de uma questão da forma do discurso, mas de sua produção e das condições culturais e políticas que o tornam fidedigno" (SARLO, 2007, p. 21). Nesse sentido, as condições culturais, políticas e históricas são condições possíveis que autentificam o testemunho como um dispositivo no qual o homem volta-se na sua interioridade para se descobrir e retorna novamente para fora com a descoberta da verdade do mundo.

A narrativa terapêutica que Gianecchini expressa em primeira pessoa é uma descoberta de si, mas o ethos terapêutico é tanto empírico quanto ético, pois tal enunciação tem reconhecimento e identificação do outro. Ao testemunhar sobre o que acontece quando os outros pacientes internados têm um resultado positivo no tratamento, o ator denota a ideia da produção do comum da linguagem terapêutica:

Gianecchini: Nessa minha jornada no hospital, foi particularmente muito interessante porque eu convivi com muita gente. Eu fiquei numa área de transplantados. Tinha muita gente com leucemia e linfomas também.

Patrícia Poeta: Um ajudando o outro, dando força para o outro...

Gianecchini: Cada vez que tem uma superação, é uma festa. Num dos quartos, aí todo mundo se junta. Toda vez que a medula dá certo. Pega e canta assim um parabéns com bolo e tudo. A pessoa está renascendo ali. E todo mundo aparece e faz parte daquela festa.

Trata-se de uma produção do comum, incialmente, pela identificação e empatia. Esse processo está relacionado à prática de relação, vínculo e reciprocidade (SODRÉ, 2014). Nesse sentido, como relata o ator, pelo sofrimento estabeleceu-se uma relação de aproximação e cooperação afetiva, com dinâmicas comunitárias. Essa situação comum no 
hospital tornava ainda mais o ator um indivíduo comum. Então, assim, o relato dessa experiência o fazia ser considerado mais humano, próximo, crível.

\section{Novas configurações de saúde}

O ethos terapêutico e sua linguagem de superação dos próprios limites, que agora perpassa o modo de existência e de subjetivação dos indivíduos da contemporaneidade, incidem fortemente nas concepções do processo saúde-doença no século XXI. A preocupação das organizações nacionais e internacionais de saúde sobre as doenças degenerativas, como o câncer, contribui com esse novo paradigma para lidar com a saúde e o bem-estar, pois a prevenção a esses tipos de doenças está relacionada a estilos de vida e, portanto, ao gerenciamento do corpo por meio de boa alimentação, prática de exercícios regularmente e controle de vícios de todas as ordens, principalmente do fumo. A partir disso, surge na intervenção biomédica uma nova condição medicalizável e um paciente sob o risco (CASTIEL; GUILAM; FERREIRA, 2010). Na concepção de saúde contemporânea há uma consideração predominante dos estudos da epidemiologia dos fatores de risco, pois eles passam a determinar os estilos de vida considerados saudáveis e prejudiciais à saúde. Nesse sentido, "promover a saúde se vincula estreitamente à informação sobre a associação entre fatores de risco e doenças, valendo se de um discurso cuja lógica é predominantemente científica" (CZERESNIA; MACIEL; OVIEDO, 2013, p. 86).

Desse modo, é preciso entender que "risco não é apenas oposto ao acaso, por implicar um cálculo probabilístico do futuro; é também oposto ao fatalismo: o evento previsível pode ser evitado pelas ações humanas" (VAZ; CARDOSO, 2014. p. 172). Essa compressão dos autores em relação ao conceito de risco demonstra o quanto a sociedade contemporânea conta com tecnologias de poder que conferem mais responsabilidade ao indivíduo em relação ao seu estilo de vida, à sua própria saúde e, consequentemente, às doenças que apresentam ao longo da vida, num nexo causal entre comportamento de risco e adoecimento. Desta maneira, os modos de existência se deslocam do sujeito doente e saudável, pois a necessidade de se prevenir antecipadamente, a partir da enorme capilaridade dessa noção de risco no tecido social contemporâneo por meio do gerenciamento do próprio corpo e da saúde, transforma os indivíduos em doentes em potencial: “[d]iferentemente da prática moderna na qual a patologia só era detectada 
quando o sintoma se manifestava, nas sociedades em que está presente a lógica do risco busca-se descobrir a doença de forma cada vez mais antecipada" (LERNER, 2014, p. 155).

No momento em que o ator explica como foi a descoberta da doença, pode-se notar presente a concepção de saúde-doença na contemporaneidade. Mesmo que o ator relate não acreditar que estava com câncer, supostamente por adotar um estilo de vida saudável recomendado como forma de prevenção dessa e de outras doenças degenerativas, a sua narrativa da descoberta do câncer expressa a ideia de que somos doentes em potencial e que, portanto, é preciso um exame detalhado sobre nosso corpo para que se possa descobrir a doença na sua forma inicial, ampliando as possibilidades de cura. Gianecchini destaca, em sua fala, que iniciou o tratamento após dois meses do diagnóstico, fazendo desse processo como algo raro e perigoso:

Patrícia Poeta: Você descobriu que estava com câncer em julho deste ano, que sintomas que você teve que levaram você a procurar um médico, a fazer os exames?

Gianecchini: Pois é, é muito maluco, porque os sintomas são todos, que poderiam ser doenças banais. Eu comecei com alergia e a garganta começou a ficar com alguns gangliozinhos. E eu sempre tive muito problema de garganta. Então, você acha que é uma bactéria. Eu fiz todos os exames de bactérias e vírus que poderia ser, e deu tudo negativo. E aí, um dia começou a suspeitar e vamos fazer uma análise do gânglio, enfim. Eu comecei o tratamento quase dois meses depois dessa suspeita de um ter um câncer raro. É um linfoma muito raro. Então, particularmente é mais difícil de diagnosticar.

Ao discutirmos sobre tal configuração do valor de adoecer na cultura contemporânea, entendendo a dinâmica midiática como prática social (COULDRY, 2004), observamos neste trabalho uma manifestação da linguagem terapêutica e as concepções de saúde na contemporaneidade traz novas atribuições de cuidado

Durante a entrevista é possível destacar alguns elementos da narrativa em que o ator mobiliza a relação de amor e de carinho entre o ator e o pai, que é mostrado e dito por Gianecchini; como também no momento final em que se emociona ao agradecer pelo apoio de Patrícia Poeta e toda a equipe. Nota-se também que na sustentação da posição de um guerreiro, reforçada pela linguagem terapêutica, em alguns momentos os seus gestuais apresentam uma tensão e incerteza no que é dito como uma pessoa forte. Numa passagem (Figura 2), Patrícia chega a questionar se há momentos de insegurança e tristeza: 
Patrícia Poeta: Em nenhum momento bateu uma tristeza, uma insegurança, nenhum sentimento assim?

Gianecchini (tensão ao passar as mãos pelo pescoço): Teve, a gente tem todos os momentinhos né. Tem umas fases que a gente pensa também. Poxa é puxadinho o negócio, é meio barra pesada mesmo. Mas ao mesmo tempo você começa no próximo momento, você começa a ver que está tudo tão bem, sabe. E aí é o momento que você fala assim: ok. E passa.

Figura 2 - Gianecchini apresenta gestos de tensão durante entrevista

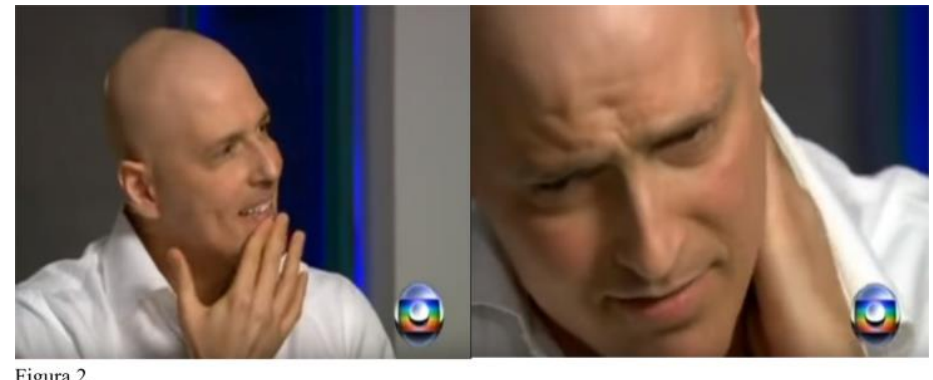

Fonte: print da entrevista (GIANECCHINI, 2011)

Nesse momento, a entrevista expressa a ideia de que é preciso ser forte, atrelada à linguagem terapêutica, e em outros, demonstra sensibilidade e afetividade - como nas lágrimas derramadas no final da entrevista concedida ao Fantástico, tendo como interlocutora a jornalista Patrícia Poeta. Nesse sentido, diferentes formas de sentimentos relacionam-se com a linguagem terapêutica: pela força (característica recorrentemente associada ao masculino e que na cultura terapêutica se exige "força interior", autoestima, autocontrole, capacidade de autoaprimoramento) e pelas lágrimas (expressão do sofrimento, da humanidade, da falibilidade, mas também do afeto, do vínculo, da relação com a entrevistadora e, sobretudo, com o público.

\section{Considerações finais}

Como vimos, o ethos terapêutico da cultura contemporânea coloca a autorrealização e a gestão eficiente de si como condições básicas para a produção de subjetividade, da mesma forma que o reconhecimento do testemunho como a produção de mais verdade também associa-se com essa configuração da vida social pelos valores de autoestima e autogestão. Assim, a experiência torna-se capaz de descobrir o sentido da vida e do mundo pelo sofrimento vivido, e somente o eu poderá retomar o controle de si. No entanto, essa 
experiência não é apenas uma forma de lidar consigo mesmo, mas produz uma ética da existência baseada no seu compartilhamento midiático.

No contexto atual, os dispositivos midiáticos se reconfiguram como uma das práticas sociais em que a lógica pós-disciplinar da performance de superação dos sujeitos em sua interioridade se expressa. A construção da subjetividade das celebridades tinha como valor e reconhecimento o endeusamento e perfeição dados pelo público. No entanto, permeados pelas tecnologias da mídia, nas quais o público também pode ser digno de reconhecimento, ocorrendo uma convergência entre público-celebridade, é que os famosos estão cada vez mais humanos e sofredores, sua realidade não é mais perfeita. Assim, o que quero ser/assim como sou não tem mais valor diante da ideia sou como vocês. É nesse sentido que a linguagem terapêutica é um comum compartilhado entre os sujeitos que ajudam um ao outro para que cada um individualmente retome `à gestão de si, tanto celebridades quanto indivíduos comuns precisam ser guerreiros.

Essa batalha de Gianechini contra o câncer (como assim foi visto pela entrevista) é frequentemente expressa como uma jornada emocionalmente complicada: a doença similar à do pai que acabara de morrer. A narração pública dessa jornada é, entre muitas outras coisas, um meio de tentativa de autovalidação e, muitas vezes, de exposição do autoaprimoramento da celebridade. Nestes roteiros de narração da vida, a figura da celebridade testemunha ao público a história do seu sofrimento, seus problemas e dificuldades. Também operam como agentes difusores do discurso terapêutico, baseado especialmente na autoestima e na autorrealização. Um contrato parece ser negociado no qual a divulgação pessoal "autêntica" ou "verdadeira" é colocada como parte fundamental da relação entre a celebridade e seu público.

Cada vez mais, o testemunho afirma-se como uma exigência de exposição da capacidade de superação dos problemas (sejam eles quais forem). Isso permite validar os indivíduos como detentores de um capital emocional tamanho, de tal grau de resolução psíquica pessoal, que podem inclusive testemunhar como "guerreiros" ou "sobreviventes" e estimular outros a buscarem autoconhecimento e mudança pessoal.

$\mathrm{Na}$ análise da entrevista com o ator Reynaldo Gianecchini, consideramos que o testemunho midiático de um sobrevivente se dá por uma enunciação composta pela cenografia, pelas vestimentas e pela disposição do corpo, os quais criam uma ambiência intimista em associação à narrativa textual. A linguagem visual caracteriza-aw em planos mais fechados no ator (primeiro plano e close up), captando os movimentos de emoção e 
comoção, e, em alguns momentos, de tensão. Portanto, o testemunho de uma história de superação tangenciada pela vida/morte na mídia se constitui em uma performance que engloba não só o que se é falado, mas a maneira como se fala, o movimento dos corpos, dos gestos e das expressões faciais dos personagens da cena.

A partir desta performance de um testemunho intimista, compreendemos que o próprio dispositivo midiático, neste caso a televisão, configura-se como uma testemunha e convoca a audiência a também se tornar testemunha da história, pois na enunciação cria-se sensações de aproximações, identificações e reconhecimento entre o público e a celebridade. A entrevistadora Patrícia Poeta também transforma-se em testemunha com Guianecchini por apresentar em suas intervenções uma aproximação e intimidade com o ator anteriores àquele momento da entrevista. Assim, o testemunho intimista é enunciado na mídia, mas também pela e por meio dela e dos seus interlocutores, que, nesta análise, são o ator e a jornalista e apresentadora.

0 tom íntimo e a presença regular de intercessores televisuais criam novos tipos de interação social, que Horton e Wohl (1986) chamam de "interação parasocial". A produção regular de figuras familiares produz uma crença no público: essas figuras também o conhecem, e essa familiaridade são apegos e direitos criativos. Daí os incontáveis malentendidos que forçam os animadores a cultivar esse elo à distância, tornando impossível alcançar intimidade, viver em um oximoro de proximidade distante. Assim, a televisão estabelece formas padronizadas de familiaridade pública. $\mathrm{Na}$ entrevista com o ator, pontuamos algumas delas: a casa, o espaço doméstico, a fala coloquial, a proximidade corporal entre entrevistadora e entrevistado, os contatos corporais (especialmente pelas mãos, em gestos de apoio), o acolhimento, a familiaridade.

Em primeiro lugar, a fala íntima deixou de ser totalmente privada, desde o momento em que fora abundantemente socializada nos consultórios dos psiquiatras, nas terapias de grupo e de autoajuda, nos programas de televisão. Um abundante repertório das formas de falar de seu sofrimento aos profissionais do sofrimento (e não mais na família ou no círculo social), ou até mesmo escrevê-lo em mensagem endereçada por muitos anos a revistas ou programas de TV, está disponível. Nesse contexto, é cada vez mais comum (e socialmente esperado) que celebridades e anônimos falem sobre si, sobretudo de seus sofrimentos e suas frustrações, por meio de mídias. Em geral, apresentam fragmentos de histórias da vida, contam suas histórias pessoais na família ou na sociedade. Eles promovem a figura da testemunha que conta sua própria existência e suas próprias experiências. Como acontece 
com Gianecchini, eles se dedicam à narrativa de si. Exibem suas experiências individuais nas cenas artificiais criadas para eles pela televisão, onde experimentam suas habilidades interpessoais e a exposição de sua personalidade.

Em outro aspecto, o que deve ser feito dessa aparente fusão de aspirações de autonomia individual e autorrealização com técnicas de gestão para a disciplina e o controle da subjetividade? A ética da autenticidade, ao que se mostra na entrevista aqui analisada, foi adaptada às estratégias de autogestão apregoada no contexto contemporâneo. Tal ética, assim, foi transformada numa forma de libertação coerciva ou de liberdade forçada (num imperativo da liberdade). Dessa forma, a entrevista com Gianecchini fornece um modelo cultural para dar sentido a um processo de subjetivação que incorpora o autocuidado à relação que o indivíduo assume consigo mesmo. A busca pelo "eu verdadeiro" é um princípio organizador para estratégias de autogestão que colocam em extinção ideias de responsabilidade pública e coletiva e que apoiam uma noção extremamente privatizada de autorrealização individual. No fim, cabia a Gianecchini elevar a autoestima para poder superar a doença. Esta é uma questão de autogestão emocional, que, aos olhos do público, assume um caráter de autenticidade.

\section{Referências}

AMOSSY, R. O ethos na intersecção das disciplinas: retórica, pragmática, sociologia dos campos. In AMOSSY (org.). Imagens de Si no Discurso: a construção do ethos. São Paulo: Contexto, 2018. p. 9-28.

ARFUCH, L. 0 espaço biográfico: dilemas da subjetividade contemporânea. Rio de Janeiro: EdUERJ, 2010.

BELLAH, R. Tokugawa Religion. New York: Free Press, 1985.

CASTIEL, L. D.; GUILAM, M. C. R.; FERREIRA, M. S. Correndo o risco: uma introdução aos riscos em saúde. Rio de Janeiro: Editora Fiocruz, 2010.

COULDRY, N. Theorising media as practice. Social Semiotics, v. 14, n. 2, 2004

CZERESNIA, D.; MACIEL, E. M. G. S; OVIEDO, R. A. M. Os sentidos da saúde e da doença. Rio de Janeiro: Fiocruz, 2013.

EHRENBERG, A. 0 culto da performance: da aventura empreendedora à depressão nervosa. Aparecida: Ideias \& Letras, 2010. 
FOUCAULT, M. História da Sexualidade I: a vontade de saber. Rio de Janeiro: Edições Graal, 1977.

FOUCAULT, M. Uma estética da existência. In: FOUCAULT, M. Ditos e escritos. v. 5. Rio de Janeiro: Forense Universitária, 2010. p. 288-293.

FRANÇA, V.; SIMÕES, P. Celebridades como ponto de ancoragem na sociedade midiatizada. Revista FAMECOS: mídia, cultura e tecnologia, Porto Alegre, v. 21, n. 3, 2014.

FUREDI, F. Therapy culture: cultivating vulnerability in an uncertain age. London: Routledge, 2004.

GIANECCHINI, R. Fantástico entrevista o ator Reynaldo Gianecchini: Eu quero a vida. Entrevista concedida a Patrícia Poeta. Rede Globo: 20 nov.2011. 1 vídeo (12m:14s). Disponível em: https://www.youtube.com/watch?v=COd--SykDGs. Acesso em: $10 \mathrm{abr}$. 2017.

HARPER, S. Madly famous: narratives of mental illness in celebrity culture. In: REDMOND, Sean; HOLMES, Su (org.). Framing celebrity: new directions in celebrity culture. London: Routledge, 2006. p. 311-328.

HOLMES, S. 'Starring... Dyer?': Re-visiting Star Studies and Contemporary Celebrity Culture. Westminster Papers in Communication and Culture, London, v. 2, n. 2, p. 6-21, 2005.

HORTON, D.; WOHL, R. Mass communication and para-social interaction: observation on intimacy at a distance. In: GUMPERT, G.; CATHCART, R. Inter/Media: interpersonal communication in a media world. New York: Oxford University Press, 1986. p. 215-229.

ILLOUZ, E. Oprah Winfrey and the glamour of misery: an essay on popular culture. New York: Columbia University Press, 2003.

ILLOUZ, E. Saving the modern soul: therapy, emotions, and the culture of self-help. Los Angeles: University of California Press, 2008.

ILLOUZ, E. 0 amor nos tempos de capitalismo. Rio de Janeiro: Jorge Zahar Editor, 2011.

LERNER, K. Doença, mídia e subjetividade: algumas aproximações teóricas. In: LERNER, K.; SACRAMENTO, I. (org.). Saúde e jornalismo: interfaces contemporâneas. Rio de Janeiro: Ed. Fiocruz, 2014. p. 151-161.

LITTLER, J. Making fame ordinary: intimacy, reflexivity and 'keeping it real'. In: RUTHERFORD, J. (ed.). Mediactive. London: Lawrence \& Wishart, 2004. p. 8-25.

MAINGUENEAU, D. A propósito do ethos. In: MOTTA, A. R.; SALGADO, L. (org.). Ethos discursivo. São Paulo: Contexto, 2008. p. 11-30.

MARSHALL, P. D. Celebrity and power. Minneapolis: University of Minnesota Press, 1997. 
MORIN, E. Cultura de massas no século XX: neurose. São Paulo: Forense Universitária, 1979.

PINTO, M. Retórica e análise de discursos. In: SACRAMENTO, I.; LOPES, F. L. Retórica e mídia: estudos ibero-brasileiros. Florianópolis: Insular, 2009. p. 37-47.

RADSTONE, S. Cultures of confession/cultures of testimony: turning the subject inside out. In: GILL, J. (org.). Modern Confessional Writing. London: Routledge, 2006. p. 166-180.

REDMOND, S. Intimate fame everywhere. In: REDMOND, S.; HOLMES, S. (ed.). Framing celebrity: new directions in celebrity culture. London: Routledge, 2006. p. 27-44.

RIEFF, P. The triumph of the therapeutic. London: Harper Collins Publishers, 1966.

ROJEK, C. Celebridade. São Paulo: Rocco, 2008.

ROSE, N. Governing the soul: the shaping of the private self. London: Routledge, 1990.

ROSE, N. Inventing our selves. Cambridge: Cambridge University Press, 1996.

SACRAMENTO, I.; BORGES, W. C. A retórica da medicalização e a justificativa moral para a cirurgia baritátrica nos relatos de celebridades. In: D'AVILA, Cristiane; TRIGUEIROS, Umberto (org.). Comunicação, mídia e saúde. Rio de Janeiro: Luminatti Editora, 2017a. p. 155-180.

SACRAMENTO, I.; BORGES, W. C. Confiança e sinceridade numa enunciação midiatizada: o ethos testemunhal de Fábio Assunção e o abuso de drogas. In: OLIMPIO-FERREIRA, M.; GRÁCIO, R. A. (org.). Retórica e comunicação multidimensional. Coimbra: Grácio Editor, 2017b. p. 65-88

SACRAMENTO, I.; RAMOS, D. Documentando a superação: Demi Lovato: Stay Strong e o discurso terapêutico contemporâneo. Verso e Reverso, São Leopoldo, v. 32, n. 79, p. 59-72, jan./abr. 2018.

SACRAMENTO, I. Tornando a dor visível: o ethos terapêutico em narrativas testemunhais de celebridades sobre o câncer. Ciberlegenda, Niterói, n. 32, p. 109-122, 2015.

SARLO, B. Tempo passado: cultura da memória e guinada subjetiva. São Paulo: Companhia das Letras, 2007.

SENNETT, R. 0 declínio do homem público: as tiranias da intimidade. Rio de Janeiro: Record, 1999.

SODRÉ, M. A ciência do comum: notas para o método comunicacional. Petrópolis, RJ: Vozes, 2014.

VAZ, P.; CARDOSO, J. Risco, sofrimento e política: a epidemia de dengue no Jornal Nacional em 2008. In: LERNER, K.; SACRAMENTO, I. Saúde e jornalismo: interfaces contemporâneas. Rio de Janeiro: Editora Fiocruz, 2014. p. 165-182. 
VAZ, P. 0 inconsciente artificial. São Paulo: Unimarco Editora, 1997.

\title{
The ethos of a warrior: the testimony of Reynaldo Gianecchini on cancer
}

\begin{abstract}
Based on reconfigurations in the production of subjectivity by the circulation of the therapeutic ethos in the contemporary world, this work analyzes the interview of the actor Reynaldo Gianecchini in TV Globo's Fantástico program, considering not only the textual content, but the enunciative form of an intimate testimony crossed by the ideals of overcoming and selfresponsibility in the recovery of autonomy (life) in the face of the experience of a cancer treatment process.
\end{abstract}

\section{Keywords}

Testimony. Celebrity. Television. Cancer. Ethos therapeutic.

\section{Autor correspondente}

Roberto Abib

comunicacaoabib@gmail.com

\section{Como citar}

ABIB, Roberto; SACRAMENTO, Igor. O ethos de um guerreiro: o testemunho de Reynaldo Gianecchini sobre o câncer. Intexto, Porto Alegre, n. 52, e-93786, jan./dez. 2021.

DOI: http://dx.doi.org/10.19132/1807-8583202152.93786

Recebido em 17/06/2019

Aceito em 26/09/2019 